\title{
Prehistoria investigada, prehistoria divulgada. Tratamiento periodístico del acervo prehistórico y arqueológico en prensa diaria
}

\section{Researched prehistory, popularized prehistory. Journalistic treatment of the prehistoric and archaeological heritage in the media}

\author{
María Dolores Meneses Fernández ${ }^{1}$
}

\begin{abstract}
RESUMEN
Los descubrimientos arqueológicos son hechos científicos que atraen la atención de los medios de comunicación hasta el punto de haberse convertido en unos contenidos habituales de la información periodística. Cuando se informa de hallazgos arqueológicos, la investigación prehistórica traspasa el nivel de la comunicación científica para convertirse en materia prima periodística, pasando al nivel de la comunicación social. La incorporación de contenidos científicos al discurso público obedece a tratamientos periodísticos dispares, según prime en la producción del texto informativo el enfoque periodístico especializado o el periodístico generalista; también influye en la calidad
\end{abstract}

\begin{abstract}
The archaeological discoveries are scientific facts that attract attention of media to till become usual contents of journalistic information. When informing about archaeological discoveries the prehistoric research goes beyond the scientific communication level to be transformed in journalistic raw material, going to level of social communication. The involvement of scientific contents to the public discourse obeys to different journalistic treatments, according to have priority on the text production the specialized or generalist journalistic approach. Furthermore, the reciprocal knowledge of the research system and the informative system has influence on the
\end{abstract}

1 Universidad de La Laguna. C.A. de la UNED de Tenerife. 
informativa el conocimiento mutuo del sistema investigador y del sistema

informativo. Este estudio tiene como objetivo indagar en los rasgos que caracterizan la difusión del acervo prehistórico y arqueológico por los medios de comunicación social, en un caso de prensa diaria en un ámbito regional.

PALABRAS CLAVE

Prehistoria y prensa, Arqueología y prensa, periodismo científico. informative quality. This paper has the objective to inquire in the characteristics of the prehistoric and historic diffusion by the social media, in a regional journal case.

\section{KEY WORDS}

Prehistory and press, Archaeology and press, scientific journalism.

\section{INTRODUCCIÓN}

La particularidad que podría destacarse en este apartado introductorio para ubicar al lector, es que el enfoque de este trabajo aúna las visiones académicas compartimentadas de dos científicos sociales con campos de investigación y objetos de estudio propios e independientes: el prehistoriador formado en las facultades de Historia, y el comunicólogo (o licenciado en Periodismo) formado en las facultades de Ciencias de la Información o de la Comunicación. Ambas perspectivas se reúnen en quien escribe estas líneas; con esa doble visión se aborda la dicotomía anunciada en el título: analizar el tratamiento que los avances y descubrimientos de la Arqueología prehistórica reciben en los medios de comunicación, de forma específica en los espacios periodísticos, sean informativos, interpretativos o de opinión.

Cada día, y de manera más patente en los meses estivales - cuando la serpiente informativa de verano marca el ritmo de la actualidad por la disminución de la información política, económica y administrativa-, prensa, radio, televisión e Internet incluyen noticias sobre descubrimientos prehistóricos acaecidos en cualquier parte del mundo, y presentados por los medios periodísticos españoles como bocanadas de aire fresco entre la priorizada información política, económica nacional e internacional. Las hemerotecas, videotecas y fonotecas muestran cómo una parte de los contenidos informativos del discurso periodístico trata de descubrimientos arqueológicos - prehistóricos, antiguos o medievales- cuyo tratamiento periodístico es lo que interesa analizar en estas páginas.

Tal y como dice la catedrática de Periodismo Especializado Montserrat Quesada (1998), ya se ha superado el mito de que los medios de comunicación sirvan a los intereses generales de la ciudadanía. Según esta autora, el debate se centra en una realidad tangible que eleva a mito, precisamente, la concepción opuesta: que los medios de comunicación sirven a los intereses de las empresas, instituciones, partidos y demás entidades que los financian. Esta realidad obliga a mirar 
con otra actitud a los medios de comunicación, teniendo en cuenta más que nunca el fundamento académico y deontológico de la profesión periodística.

Este estudio se ocupa de un ejemplo de prensa diaria de información general, la editada en Canarias, si bien debe precisarse que las informaciones estudiadas aluden a hechos noticiosos producidos por la investigación prehistórica y arqueológica en las Islas y en cualquier parte del mundo, recogidos por la prensa insular.

\section{EXPOSICIÓN}

El interés por el objeto de esta investigación toma forma a medida que la observación de los medios periodísticos de los años noventa nos hacía intuir un comportamiento peculiar en la difusión de información generada por las disciplinas vinculadas al patrimonio histórico (Prehistoria, Historia, Arqueología, Antropología o Etnografía). Este comportamiento, que hacíamos depender de la noción clásica de línea editorial, parecía encerrar un propósito de influencia social que había que verificar analizando los contenidos periodísticos alusivos a descubrimientos prehistóricos. Supusimos que el proceder periodístico observado respondía a una estrategia editorial que marcaba las pautas y creaba rutinas al informar del patrimonio arqueológico. Esa pauta hacía intuir propósitos de construcción y afirmación de una idea de canariedad.

La imagen que de sí mismo tiene cualquier grupo social se ve influida por el conocimiento que tiene de la realidad no sólo inmediata, sino de la realidad en sentido amplio, la que sobrepasa las fronteras de lo próximo, lo cercano, lo propio o «lo nuestro", según una expresión popular canaria. El acervo prehistórico y arqueológico estaba y está presente en los contenidos de los medios de comunicación; el rastreo de su tratamiento periodístico mediante métodos propios de la Periodística, como es el análisis de contenido, permite aproximarnos al papel desempeñado por los medios informativos en los usos sociales y en la construcción de una imagen mediática de la etapa prehispánica de las Islas y de sus restos arqueológicos. Usos que se alejan de la consideración de los descubrimientos prehistóricos en su dimensión científica histórica e incluso divulgativa para adentrarse en la manipulación, espectacularización y sensacionalismo.

En esa construcción mediática subyace la influencia (social, política e ideológica) de los medios de comunicación, el perfil de las audiencias, el conocimiento que tiene el periodista de las premisas teóricas y metodológicas de la disciplina de la que informa, y el conocimiento que tienen las fuentes expertas (prehistoriadores y arqueólogos en este caso) del funcionamiento de la industria periodística y del sistema informativo.

Nuestro interés se centra en los contenidos de cuatro periódicos diarios canarios, los de más difusión e implantación en la sociedad canaria; tres de ellos existen aún, aunque dos fusionados en una misma cabecera. Dos de cada provincia: 
La Provincia (matutino creado en 1911) y Diario de Las Palmas (vespertino, 1893) editados en Las Palmas de Gran Canaria; El Día (matutino fundado en 1910) y La Tarde (vespertino, 1927), de Santa Cruz de Tenerife. El perfil de los cuatro diarios revela dos modelos empresariales: el familiar (El Día propiedad de los Herederos de Leoncio Rodríguez y La Tarde, de M. Real y Cía, S.L.) y el gran grupo de comunicación (La Provincia y Diario de Las Palmas, de Editorial Prensa Canaria adquirida por Prensa Ibérica).

El periodo estudiado es la Transición Democrática por ser una etapa de gran interés periodístico e histórico, en los que las competencias patrimoniales correspondían al Gobierno de la nación, pero en la que se redactan y aprueban los Estatutos de Autonomía de las distintas Comunidades, Leyes, por cierto, especialmente sensibles al patrimonio histórico local. Los periódicos estudiados son todos los números editados en 1975 y 1982. Como apunte diremos que en el momento de realizarse este trabajo, las Comunidades Autónomas están inmersas en el proceso de renegociación y aprobación de sus respectivos Estatutos de Autonomía.

2.260 números de periódicos y 9.252 informaciones de ciencia y cultura seleccionadas integran el corpus analizado, entre las que corresponde delimitar el peso de las que tratan de prehistoria y arqueología. Estas informaciones corresponden a las secciones Local, Región o Canarias, Nacional, Internacional o Extranjero, Opinión, Lectores, Última Hora o Cierre e incluso Sucesos, sin olvidar la primera y la última plana ni las páginas dominicales extras.

Recopilados los varios miles de textos periodísticos, la temática que tratan apunta a los grandes conceptos cultura de elite, cultura oficial, popular.

Ciro F.S. Cardoso (1981: 167-170) afirma que en las disciplinas humanísticas y sociales, el planteamiento de hipótesis que orienten el proceso de investigación es una tarea harto delicada. Lo que sí podemos enunciar como proposición general es que la prensa canaria muestra una dicotomía entre las informaciones culturales y científicas estrictas, y los hechos informativos derivados de la noción de cultura popular.

Las informaciones referidas a la cultura popular son de ámbito local y elaboración propia (redactadas por los diarios canarios, no por agencias de noticias), y superan a las generadas por fuentes primarias expertas pertenecientes a centros superiores de educación e investigación, estén o no radicados en Canarias.

Otra parte de las informaciones de la prensa local parece responder a los conceptos de Periodismo Cultural y Periodismo Científico predominantes entonces, pero ese hecho no afecta al tratamiento populista de los temas relacionados con Canarias.

La impronta editorial de los rotativos se percibe en el enfoque dado a la noticia por el redactor, como marca distintiva superpuesta a los contenidos culturales y científicos tratados. 
Las teorías comunicológicas y periodísticas recogen fenómenos consistentes en la sanción y ratificación mediática de modelos de creación, difusión y consumo de conocimientos y productos culturales; estos fenómenos dependen de los sistemas económicos y políticos que articulan la sociedad. Esta situación, sin duda compleja, es a la vez causa y efecto de las relaciones socio-culturales en las que los contenidos identitarios -entre ellos el patrimonio prehistórico y arqueológicoes sometido a usos sociales, políticos e ideológicos.

La revisión bibliográfica (en especial las tesis doctorales de la base de datos TESEO) pone de manifiesto la carencia de estudios sobre la información de ciencia y cultura en prensa diaria local. Esto contrasta con el hecho de que se considere que el binomio comunicación-cultura suponga una de las tendencias mejor definidas en el panorama mediático contemporáneo; cultura e identidad, y la nueva configuración de la cultura de elite y cultura popular son dos facetas de esta tendencia (Mingolarra, J.A., 1999).

La historia del periodismo canario rebasa los dos siglos; desde sus orígenes ha sido vocero de momentos de auge y euforia de la cultura en Canarias, y también es testigo de episodios de vindicación de esa cultura. Desde los años setenta del siglo XX se asiste al más reciente de estos intentos de reafirmación de 'lo cultural canario', prolongado hasta la actualidad. Los periódicos son uno de los canales, junto con la política educativa y la divulgación, incluidos los museos de prehistoria, arqueología y antropología.

José Antonio Mingolarra (1999) afirma que nuestros trazos constitutivos vienen configurados por la memoria individual y colectiva, y que la memoria colectiva reciente contribuye a la comprensión del porqué y del cómo de nuestro imaginario cultural actual, diferenciando y estableciendo los indicadores culturales que permanecen como referencia obligada y explicable en nuestra forma de hacer hoy. La cultura - siguiendo con este autor- se manifiesta, se representa, encierra valores que un comportamiento político ha construido en el colectivo social.

Existe en Canarias una idea de cultura favorecida por la información periodística y por los medios de comunicación en general, que debe parte de su razón de ser a una situación histórica determinante. El contexto histórico es referencia permanente. Pero de igual manera lo es el concepto contemporáneo que los periodistas - y demás actores participantes en la prensa- manifestaban en sus textos informativos sobre el momento histórico vivido y sobre el pasado remoto traído al presente. Porque la prensa no sólo construye el presente. El periodismo puede considerarse un método de interpretación de la realidad social, como afirma Lorenzo Gomis (1991); sí, pero matizamos los supuestos en los que este autor sustenta el periodismo como método de interpretación de la realidad social, puesto que no es sólo la realidad actual la que interpreta: el periodismo se nutre del presente pero también del pasado. De hecho, una de las vías de representación y utilización del pasado en el presente son los periódicos. 
Dado el ámbito histórico, antropológico y sociológico en el que se desarrollan las dos disciplinas que nos interesan -la Prehistoria y la Periodística-, es oportuno citar unas palabras de Jesús Martín Barbero (1987: 13) sobre el hecho de que son los medios de comunicación el lugar en el que se organiza y piensa la propia comunicación, en una especie de egocentrismo que conduce a hablar de todo pero sólo desde sí mismo. Esa situación convertida largo tiempo en un lastre para el periodismo ve una salida del túnel en el Periodismo Especializado; una disciplina joven y no obstante incluida como materia troncal en los planes de estudio desde que se crearan los estudios universitarios de Periodismo y las facultades de Ciencias de la Información en España, en 1971-1972.

Pero no debemos engañarnos. Como reconoce el profesor Ramon Reig (2004), en la actualidad un estudiante universitario de Ciencias Sociales posee un desconocimiento casi absoluto de la evolución histórica y de las corrientes de pensamiento; carece, por tanto, de capacidad interpretativa estructural. Tal apreciación podemos verificarla en las facultades de Historia y en las de Ciencias de la Información. No obstante, cada vez son más frecuentes las situaciones en las que nuestros alumnos de Prehistoria y Arqueología llegan al aula con noticias de hallazgos que han leído o visto en los medios de comunicación. Los medios de comunicación tienen el poder de mitificar cualquier faceta de la realidad, más allá del sentido común y de la evidencia científica. Y los descubrimientos arqueológicos son especialmente sensibles a tal proceso, máxime cuando hay un caldo de cultivo sociocultural y político.

La existencia de periodistas especializados salidos de las universidades no evita tratamientos periodísticos distorsionados de avances en la Prehistoria considerados noticiables; como la existencia de licenciados en Historia tampoco evita la alusión de descubrimientos prehistóricos en foros pseudocientíficos. De ahí el redoblado compromiso de los medios de comunicación al informar de ellos.

Los miles de textos periodísticos analizados aportan miles de datos y resultados que revelan la importancia en el periodismo científico de los contenidos sobre Medicina (si se excluyen los políticos, económicos y deportivos, son los que más cobertura reciben por ser una información sensible socialmente), Astronomía y Prehistoria-Paleontología-Antropología.

La prensa editada en Canarias de principio de los años noventa nos permite el análisis del tratamiento periodístico de un tipo de restos prehistóricos, emblemáticos por simbólicos, de la etapa prehispánica de las Islas Canarias: las momias. La cobertura informativa del I Congreso Internacional sobre Momias y la exposición asociada de momias traídas a Tenerife procedentes de culturas prehistóricas de varios países, celebrado en enero y febrero de 1992, revelan una imagen periodística de la prehistoria de Canarias (de la etapa prehispánica, si se prefiere) como una realidad cercana, "la nuestra», "la de nosotros», la de «nuestros ancestros». 
Si comparamos este tratamiento periodístico de la prehistoria canaria con descubrimientos arqueológicos de territorios lejanos, por ejemplo la cobertura informativa que televisiones y periódicos españoles dieron en sus respectivos momentos del hallazgo del «hombre de los hielos», de Toumaï (Sahelanthropus tchadensis), del hombre de Flores (u Homo floresiensis, cuya atribución taxonómica del Homo erectus al Homo sapiens recogieron los medios periodísticos), de Pau (Pierolapithecus catalaunicus o «el primer catalán», como publicaban muchos diarios españoles) o de los descubrimientos casi cada verano en Atapuerca, varía de forma sustancial. En unos casos se trata de la prehistoria «de otros», de descubrimientos lejanos aunque curiosos; en otros se habla de «nuestros ancestros», "de nuestros antepasados», de algo próximo. Dependiendo del medio de comunicación y de la formación del periodista, unas noticias enfocarán lo estrictamente científico o, si acaso, el componente de curiosidad. En otras noticias, la exaltación y la espectacularidad la reducirán al ámbito del sensacionalismo.

$Y$ hemos de tener en cuenta que una de las funciones que los teóricos atribuyen al Periodismo especializado (una de cuyas modalidades temáticas es el Periodismo científico) es la de ser canal de comunicación entre científicos y sociedad, pero también, y no ha de olvidarse, entre los científicos mismos. Cada vez con mayor frecuencia, el investigador se informa de los últimos avances en su disciplina por los medios de comunicación que por las publicaciones científicas, porque los centros de investigación y sus expertos participan en la dinámica de obtener rendimiento publicitario de los resultados de sus investigaciones en los medios de comunicación, sobre todo cuando está en juego la concesión de proyectos y la obtención de fondos públicos o privados para la investigación.

La sociedad de la complejidad actual exige un periodismo de complejidad. Esta respuesta periodística afecta de lleno a la formación de los periodistas y, ante todo, al compromiso de las empresas informativas (diarios, revistas, canales de televisión, emisoras de radio e Internet). Ese periodismo de complejidad, uno de cuyos ejes es el periodismo especializado como forma de producir textos periodísticos basados en la especialidad temática, ha de ser capaz de valorar los productos ofrecidos a la sociedad con aspiraciones divulgativas. Productos divulgativos que incluyen los museos y las campañas divulgativas impulsadas por los partidos políticos que gobiernan en cada nivel de la Administración pública, dedicados a fomentar el patrimonio prehistórico y arqueológico. No en vano esos productos divulgativos pueden afectar al tratamiento que el periodista da del pasado en el presente.

El catedrático de Teoría de la Comunicación, Miquel Rodrigo Alsina y la profesora Catalina Gaya (2001) aciertan cuando abogan por un nuevo perfil académico del periodista de hoy, y le exigen que sea licenciado en Periodismo y antropólogo, en el sentido lato del término. Los autores se refieren a la necesidad que tiene el periodista de disponer de conocimientos antropológicos que le permitan afrontar la multiculturalidad que caracteriza la sociedad actual, generada por la in- 
migración. Esa reflexión en el eje sincrónico es aplicable al diacrónico, para exigir al periodista que contextualice los avances de la Prehistoria y la Arqueología en la dimensión científica histórica.

El tratamiento periodístico de calidad de los contenidos científicos, como son los aportados por la Prehistoria y la Arqueología, está en función directa del componente deontológico del ejercicio del periodismo. Los teóricos del Periodismo han hecho bascular la Teoría de la Responsabilidad Social de la Prensa hacia la Doctrina de la Ética Compartida o Integral. Quiere decir esto que se ha pasado de depositar la responsabilidad del acto informativo en la prensa, en las empresas periodísticas, a reconocer la cota de responsabilidad que tiene cada unos de los actores participantes en la comunicación social: empresas de comunicación, periodistas, fuentes, lectores, telespectadores, radioyentes usuarios de Internet, asociaciones de consumidores de medios de comunicación y fuentes primarias expertas.

El poder de los consumidores de periódicos, emisoras de radio y televisión es enorme. Pero ese poder es directamente proporcional a su nivel educativo, cultural y de instrucción, y también de su predisposición a la acción respecto a los medios que consume. Pero ese poder también está presente en las fuentes expertas que proporcionan información especializada a los periodistas y de su presencia a medios de comunicación; además, en las fuentes suele coincidir también la condición de consumidor de medios.

Es un reto instruir al ciudadano en las particularidades del funcionamiento de los medios de comunicación y del sistema informativo de una sociedad; nos referimos al ciudadano como consumidor de mensajes periodísticos o como fuente experta. Los periodistas profesionales reciben esta instrucción en los estudios que cursan en la licenciatura de Periodismo, lo cual no es garantía de su observancia deontológica. Y la mayoría de la población se hace una idea de los medios periodísticos desgajados de los imperativos y rutinas que marcan su funcionamiento.

Los medios de comunicación están presentes en la vida cotidiana de cualquier individuo y llegan a pautar su actividad diaria, además de influir en la toma de decisiones. En la sociedad de la información y del conocimiento, en todos sus niveles de difusión (local, comarcal, regional, nacional y supranacional), sean privados o públicos, persiguen, más allá del servicio público, influir en el poder y en la sociedad, y lucrar (Borrat, 1989, 2000, 2004).

Vicente Salvador (2000) nos recuerda que los discursos divulgativos cumplen la función social de difusión de los conocimientos entre dos límites:

1) el superior de la investigación o avance epistemológico en el ámbito de una especialidad, y

2) el inferior de la mera transmisión de información noticiosa de carácter mediático, valiéndose de ciertos géneros de comunicación relacionados con la difusión de conocimientos especializados. 
Otros teóricos, como Pierre Bourdieu (1997), han estudiado las influencias negativas del campo periodístico sobre otros campos culturales como el científico, por su heteronomía, espectacularización y ser un simulacro falaz de democracia directa. A pesar de ello, Bourdieu ve en la difusión del conocimiento una vía de legitimación necesaria del campo científico, ya que sin la dimensión divulgadora no se podría hablar de un control democrático de la ciencia ni de una redistribución democrática del caudal de conocimiento acumulado. La condición es elevar el listón del rigor y obligar éticamente a la comunidad científica a propiciar unas condiciones de difusión óptimas, que exige ejercer un cierto control sobre los medios de comunicación.

La didacticidad (Salvador, V., 2002) cada vez más exigida al periodismo de calidad no se limita a «hacer saber» algo a los lectores o espectadores, sino que busca «hacer aprender» lo que explica. La diferencia entre «hacer aprender» y «hacer saber» es la distancia entre el polo didáctico y el polo informativo. Con esta perspectiva, el periodismo funciona como mediación indispensable, bien sea por la formación de unos cuadros de periodistas científicos o técnicos, bien sea por la consulta a los expertos.

A pesar de esta tendencia en la praxis periodística, ciertos contendidos informativos son especialmente sensibles por las consecuencias inmediatas o mediatas que producen en la sociedad. Entre ellos están los contenidos culturales identitarios, por la relevancia que han alcanzado en la sociedad multicultural, globalizada y glocalizada actual. Su complejidad exige un riguroso tratamiento, sea cual sea la clave informativa que adopte el periodista: periodismo generalista o de actualidad, periodismo especializado (científico o cultural en este caso) o divulgación científica.

Es la vía óptima para que el periodista de medios territoriales menores (locales, comarcales, provinciales e incluso regionales) no sucumba a los usos ideológicos y políticos del patrimonio prehistórico, arqueológico y etnográfico.

El tratamiento de los descubrimientos prehistóricos y arqueológicos en los medios informativos está en relación no sólo del conocimiento que el periodista tiene de las premisas teóricas y metodológicas de estas disciplinas. Pero también depende de la consideración que los prehistoriadotes - como fuentes científicastienen de los periodistas y de la consideración que la sociedad tiene de los historiadores como científicos. La segunda encuesta sobre percepción Social de la Ciencia y la Tecnología en España-2004 (2005) sitúa la Historia en el último lugar en el grado en que se consideran científicas una serie de catorce disciplinas, por detrás incluso de la astrología. Estas relaciones complejas hacen difícil evaluar la credibilidad y fiabilidad que los unos les reconocen a lo otros.

Además, el periodista científico informa a sus audiencias de los hallazgos que dan a conocer los investigadores, sean o no motivo de debates científicos más o menos controvertidos. Si a la provisionalidad de los conocimientos prehistóricos se 
suma que la Prehistoria arrastra un halo de disciplina de lo superlativo, se entiende lo fácil que es sucumbir a titulares que descubren lo más antiguo, lo más sorprendente o lo más arcaico.

La investigación hemerográfica realizada en los cuatro diarios de información general de 1975 y 1982 desvela las disciplinas que han generado noticias en Canarias.

Algunos titulares ilustrativos, citados de forma literal, son:

- «Los aborígenes isleños respetaban mucho a la mujer», en La Provincia, febrero 1975.

- Los guanches, una "ceremonia» a cuidar, en El Día, agosto 1982.

- Desde Tacoronte: los guanches, pueblo predecesor, en El Día, agosto 1982.

- Rememoración de la gesta de la raza aborigen, en Ansite

- El señor Cullen y del Castillo alzó el gánigo al grito ritual de ¡Atis, Tirma!, publicado en primera página por La Provincia, abril 1982.

- Absoluta falta de protección atómica en Gran Canaria.

- Las cuevas aborígenes servirían como refugios, en La Provincia, noviembre 1982.

— «Los guanches siguen aquí», en La Provincia, diciembre de 1982.

- «La raza guanche aun pervive», en Diario de Las Palmas, noviembre 1982.

- Un «santuario de la canariedad» a punto de perderse.

- Piden el cierre del Barranco de Guayadeque, en Diario de Las Palmas, diciembre 1982.

Algunos de los titulares hallados pueden ser considerados atemporales; otros adquieren sentido en la época a la que pertenecen y en el periódico que los publicó.

La clasificación por categorías aporta los resultados mostrados a continuación. Ha de tenerse en cuenta que la categoría Arqueología se refiere a hallazgos de la etapa prehispánica de las Islas y a actividades académicas, mientras que Patrimonio se refiere a noticias relacionadas con la conservación. Las cifras indican el número de informaciones por periódico y año: 
Diario El Día 1975 n. ${ }^{\circ}$ de informaciones

Ciencias Humanas: Arqueología 10

Ciencias Humanas: Historia de Canarias 70

Ciencias Humanas: Historia General 5

Ciencias Humanas: Patrimonio (general) 7

Ciencias Humanas: Patrimonio Artístico 18

Ciencias Humanas: Patrimonio Documental -

Ciencias Humanas: Patrimonio Etnográfico -

Ciencias Humanas: Patrimonio Histórico 10

Ciencias Humanas: Patrimonio Histórico Artístico 29

El Día 1982 n. ${ }^{\circ}$ de informaciones

Ciencias Humanas: Arqueología 16

Ciencias Humanas: Historia de Canarias 141

Ciencias Humanas: Historia General 27

Ciencias Humanas: Patrimonio (general) -

Ciencias Humanas: Patrimonio Artístico 54

Ciencias Humanas: Patrimonio Documental 3

Ciencias Humanas: Patrimonio Etnográfico 5

Ciencias Humanas: Patrimonio Histórico 17

Ciencias Humanas: Patrimonio Histórico Artístico 24

Diario La Tarde 1975

Ciencias Humanas: Arqueología 14

Ciencias Humanas: Historia de Canarias 45

Ciencias Humanas: Historia General 10

Ciencias Humanas: Patrimonio (general) 1

Ciencias Humanas: Patrimonio Artístico 26

Ciencias Humanas: Patrimonio Documental 4

Ciencias Humanas: Patrimonio Etnográfico -

Ciencias Humanas: Patrimonio Histórico 7

Ciencias Humanas: Patrimonio Histórico Artístico 26

\section{La Tarde 1982}

Ciencias Humanas: Arqueología 7

Ciencias Humanas: Historia de Canarias 15

Ciencias Humanas: Historia General 7

Ciencias Humanas: Patrimonio (general) -

Ciencias Humanas: Patrimonio Artístico 13

Ciencias Humanas: Patrimonio Documental -

Ciencias Humanas: Patrimonio Etnográfico 1

Ciencias Humanas: Patrimonio Histórico 3

Ciencias Humanas: Patrimonio Histórico Artístico
Diario La Provincia 1875

Ciencias Humanas: Arqueología 24

Ciencias Humanas: Historia de Canarias 50

Ciencias Humanas: Historia General 14

Ciencias Humanas: Patrimonio (general) 2

Ciencias Humanas: Patrimonio Artístico 5

Ciencias Humanas: Patrimonio Documental 1

Ciencias Humanas: Patrimonio Etnográfico -

Ciencias Humanas: Patrimonio Histórico -

Ciencias Humanas: Patrimonio Histórico Artístico 9

La Provincia 1982

Ciencias Humanas: Arqueología 25

Ciencias Humanas: Historia de Canarias 50

Ciencias Humanas: Historia General 17

Ciencias Humanas: Patrimonio (general) 1

Ciencias Humanas: Patrimonio Artístico 15

Ciencias Humanas: Patrimonio Documental 2

Ciencias Humanas: Patrimonio Etnográfico -

Ciencias Humanas: Patrimonio Histórico 19

Ciencias Humanas: Patrimonio Histórico Artístico 33

Diario de Las Palmas 1975

Ciencias Humanas: Arqueología 4

Ciencias Humanas: Historia de Canarias 45

Ciencias Humanas: Historia General 13

Ciencias Humanas: Patrimonio (general) 12

Ciencias Humanas: Patrimonio Artístico 9

Ciencias Humanas: Patrimonio Documental 4

Ciencias Humanas: Patrimonio Etnográfico -

Ciencias Humanas: Patrimonio Histórico 4

Ciencias Humanas: Patrimonio Histórico Artístico 9

Diario de Las Palmas 1982

Ciencias Humanas: Arqueología 10

Ciencias Humanas: Historia de Canarias 52

Ciencias Humanas: Historia General 15

Ciencias Humanas: Patrimonio (general) -

Ciencias Humanas: Patrimonio Artístico 26

Ciencias Humanas: Patrimonio Documental 4

Ciencias Humanas: Patrimonio Etnográfico -

Ciencias Humanas: Patrimonio Histórico 6

Ciencias Humanas: Patrimonio Histórico Artístico 
La categorización temática del discurso público revela la presencia continuada de la Arqueología en la información periodística. Es motivo permanente de la atención periodística y se plasma en noticias casi todos los meses. Este dato cuantitativo se complementa con el cualitativo, con el referido al tratamiento de estas noticias.

Y el discurso periodístico permite distinguir dos grandes ámbitos en el tratamiento: una profusa tarea de concienciación sobre la necesidad de estudiar la prehistoria de las Islas y de conservar el patrimonio arqueológico; y otro gran ámbito en el que destaca sobremanera el componente identitario de la prehistoria y de los restos arqueológicos. Forman parte, en el discurso de las fuentes y luego en el de los periódicos, de la 'identidad canaria'.

Para revelar esa temática se ha reducido cada texto periodístico a una de las nueve categorías temáticas de Ciencias Humanas relacionadas. Estas categorías pueden reordenarse en los enfoques que priman en el tratamiento de cada noticia:

- Aculturación: textos periodísticos alusivos al proceso cultural desencadenado durante el encuentro y posterior coexistencia de la población prehispánica y la castellana, además de otras llegadas a las Islas durante o con posterioridad al choque y al periodo de conquista.

- Antropología física: textos que aluden a los rasgos físicos de la población canaria. Implica alusiones dominantes a los habitantes prehispánicos.

- Artesanía: textos referidos a la manufactura de productos según técnicas tradicionales, fuesen prehispánicas o posteriores.

- Costumbres y tradiciones: textos referentes a costumbres y tradiciones canarias. Por ejemplo el silbo gomero, los sacrificios de animales, los juegos y deportes autóctonos, con supuesta raíz prehispánica.

- Historia de Canarias: textos en los que el autor trata algún aspecto de la Historia de las Islas, sea de época prehispánica, de la conquista, de época moderna o contemporánea.

- Identidad endógena: textos en los que se muestra o alude a cómo se ve el canario a sí mismo. Se ejemplifica en los rasgos de carácter, talante, belleza, fuerza, nobleza o complejo de inferioridad del vencido y olvidado (es el nosotros frente a los otros).

- Identidad exógena: textos en los que se muestra cómo ve el otro (el no canario) al canario. Se ejemplifica en la belleza exótica de la mujer canaria, en la dulzura del carácter y del acento, y en el aplatanamiento del canario, entre otros atributos.

- Mitos: textos sobre relatos fabulosos acontecidos en alguna de las Islas, ejemplificados con expresiones como el 'guanche buen salvaje', en la isla 
de San Borondón, en el jardín de las Hespérides o en las Afortunadas, entre otras.

- Ritos: textos sobre ceremonias conmemoradas periódicamente, por ejemplo, la fiesta de La Rama, las «bajadas» de la virgen patrona de cada Isla o las romerías, aderezadas o no con presumibles ritos prehispánicos.

- Símbolos: textos alusivos a personas, hechos, objetos o lugares emblemáticos, representativos de una identidad canaria cuasi legendaria. Por ejemplo, 'el padre Teide', la 'fortaleza de Ansite', la vasija de barro denominada gánigo o las pintaderas; elementos con una carga simbólica en general enraizada en la época prehispánica o en la conquista.

Si nos fijamos, con estas diez categorías obtenemos el mapa de la noción de "canariedad» proyectada por los periódicos locales (Meneses, M. ${ }^{a}$ D. y Hernández, H., 2004). Esta proyección periodística se basa en la visión que las fuentes expertas han manifestado al periodista o en la visión que, en este caso de la Prehistoria y la Arqueología Canarias, tiene el propio periodista. El desconocimiento de los fundamentos teóricos y metodológicos de la Prehistoria y la Arqueología explica, entre otros episodios informativos, el tratamiento descontextualizado que los periodistas de los diarios insulares hicieron de los debates que sobre los habitantes prehispánicos de Canarias tuvieron lugar en el Congreso Internacional de Momias celebrado en Tenerife en enero de 1992; por ejemplo sobre la posibilidad de que practicaran la antropofagia, ritual o no, o sus rasgos antropométricos (Meneses, M. ${ }^{a}$ D. y García, M., 2005).

\section{CONCLUSIÓN}

Como la mayoría de las instituciones, las universidades cuentan con un gabinete de prensa que actúa de enlace con los medios de comunicación del entorno geográfico; incluso algunas editan una guía de expertos en la que se inscriben profesores e investigadores a los que los periodistas pueden recurrir como fuentes. Pero los gabinetes de prensa suelen quedar reducidos a gabinetes de imagen del rectorado y a la elaboración del dossier de prensa diario; y la distribución limitada de las guías de expertos no garantiza su conocimiento y manejo por todos los medios de comunicación. Por otra parte, los gabinetes no supervisan todos los contactos entre periodistas y profesores, teniendo éstos libertad para atender a la prensa cuando les demanda información, o para dirigirse a ella por iniciativa propia. Tal circunstancia aconseja al investigador sopesar lo que dice y cómo lo dice al periodista, y supervisar qué extrae de la información facilitada. En este caso, la negociación entre fuente experta y periodista es la vía adecuada para garantizar la calidad informativa.

En cuanto al periodista y a los medios informativos, corresponde conocer su compromiso deontológico profesional. Una de sus obligaciones es ofrecer conte- 
nidos sujetos al rigor y contexto científicos. Pero para ello el redactor ha de tener experiencia en Prehistoria y Arqueología; de no ser así, como se comprueba en los titulares seleccionados, su tarea se reduce a transmitir mensajes de fuentes mejor o peor intencionadas. La experiencia en la disciplina de la que informa permite al periodista analizar los hallazgos arqueológicos antes de trasladarlos al soporte periodístico, ya que le proporciona una perspectiva crítica para sortear los riesgos de caer en lugares comunes. Como hemos afirmado en otro lugar, la información de calidad no depende sólo de las fuentes expertas consultadas por los redactores, sino también, por un lado, de la concepción previa que los periodistas tienen de los restos arqueológicos (a veces basada en conocimientos simples o en la inercia a la que llevan los componentes míticos asentados en la sociedad); e incluso, por otro lado, de lo que quieren leer los lectores, en cuyo caso el periodista no hará más que enfatizar en clichés populares no científicos.

Otra obligación es no emitir como información científico-tecnológica contenidos publicitarios. Es sabido que marcas comerciales de sectores diversos invierten fondos y ceden infraestructuras para la realización de investigaciones arqueológicas y paleontológicas; los intereses que subyacen en esta circunstancia, hasta hace pocos años inhabitual en España, complican soslayar contenidos publicitarios en las informaciones periodísticas; aun así, el periodista y su medio de comunicación han de ser cuidadosos para evitar la emisión de publicidad inserta en noticias, como viene ocurriendo en los últimos tiempos en los informativos de ciertas cadenas de televisión españolas cuando informan de hallazgos arqueológicos.

\section{BIBLIOGRAFÍA}

BorRat, H. (1989): El periódico, actor político. Barcelona, Editorial Gustavo Gili.

- (2000): «Narración y análisis de la historia inmediata social, política, económica o cultural desde las ciencias sociales", en Universitat i periodisme. Actes de les jornades sobre continguts acadèmics $i$ docència a la llicenciatura de periodisme. Bellaterra, març de 1998. Col.lecció Documents, Bellaterra, Universitat Autónoma de Barcelona, Servei de Publications, pp. 137-148.

- (2004): «Versiones mediáticas de la interacción politica», en Bello JANEIRO, D.; LóPEZ García, X. (coords.), La divulgación del conocimiento en la sociedad de la información, Santiago de Compostela, Xornadas e Seminarios, Escola Galega de Administración Pública, Xunta de Galicia, pp. 261-317.

Bourdieu, P. (1998): La distinción. Criterio y base social del gusto. Madrid, Taurus.

CARDoso, C.F.S. (1981): Introducción al trabajo de la investigación histórica. Conocimiento, método e historia. Barcelona, Crítica, Grupo Editorial Grijalbo.

CARdoso, C.F.S. y Pérez BRIGNoli, H. (1981): Los métodos de la historia. Introducción a los problemas, métodos y técnicas de la historia demográfica, económica y social. Barcelona, Crítica, Grupo Editorial Grijalbo.

GomIS, L. (1978): El medio media. La función política de la prensa. Barcelona. Editorial Mitre.

- (2004): «Para una teoría de la actualidad», en CASALS CARRO, M. J. (coord.). Mensajes periodísticos y sociedad del conocimiento, Libro homenaje al profesor José Luis Martínez Albertos, Departamento de Periodismo I, Facultad de Ciencias de la Información, Universidad Complutense de Madrid, Madrid, Editorial Fragua, pp. 347-360.

Meneses Fernández, M. ${ }^{a}$ D.; Hernández Hernández, H. (2004). «La prensa insular y la difusión de la idea de "canariedad» durante la Transición», en Casal Carro, María Jesús (coord.), Mensajes periodísticos y sociedad del conocimiento, Libro Homenaje al profesor José Luis Martínez Albertos. Madrid, Editorial Fragua, pp. 195-206. 
Meneses Fernández, M. ${ }^{a}$ D.; García Morales, M.; Estévez González, F. (2005): «Remote ancestors or scientific evidence? Pre-Hispanic mummies from the Canary Islands in the media». Journal of Biological Research, Proceedings V World Congress on Mummy Studies, Vol. LXXX, n. ${ }^{\circ}$, pp. 287-289.

MingolarRA, J.A. (1999): Tendencias actuales de la comunicación. Universidad de Verano de Adeje, (s.p.).

QuesadA Pérez, M. (1998): Periodismo especializado. Madrid, Ediciones Internacionales Universitarias, EIUNSA.

REIG GARCíA, R. (2004): «Los grupos de comunicación y el periodismo especializado», en Bello JANEIRO, D.; LóPEZ GARCíA, X. (coords.), La divulgación del conocimiento en la sociedad de la información, Santiago de Compostela, Xornadas e Seminarios, Escola Galega de Administración Pública, Xunta de Galicia, pp. 189-216.

Rodrigo Alsina, M.; Gaya Morla, C. (2001): «Medios de comunicación e interculturalidad». Cuadernos de Información, 14, Facultad de Comunicaciones, Pontificia Universidad Católica de Chile (versión electrónica).

SALVADOR, V. (2002): «Discurso periodístico y gestión social de los conocimientos: algunas observaciones sobre la didacticidad». Anàlisi: Quaderns de Comunicació i Cultura, 28, Departamento de Periodisme i Ciències de la Comunicació, Universidad Autónoma de Barcelona, pp. 107-120.

VV.AA. (2005): Percepción Social de la Ciencia y la Tecnología en España - 2004. Madrid, Fundación Española para la Ciencia y la Tecnología (FECYT). 